\title{
ADOLESCER E ADOECER: PERFIL DE SAÚDE-DOENÇA DE ADOLESCENTES DE UMA UNIDADE BÁSICA DE SAÚDE DO MUNICÍPIO DE SÃO PAULO
}

\author{
Maria Amélia de Campos Oliveira* \\ Emiko Yoshikawa Egry**

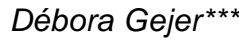

OLIVEIRA, N.A. de C.; EGRY, E.Y.; GEJER, D. Adolescer e adoecer. O perfil de saúde-doença de adolescentes de uma unidade básica do município de São Paulo. Rev.latino-am.enfermagem, Ribeirão Preto, v. 5, n.1, p. 15-25, janeiro de 1997.

O presente estudo buscou caracterizar o perfil de saúde-doença dos adolescentes usuários de uma Unidade Básica de Saúde pertencente à rede Municipal da Cidade de São Paulo. Os dados empíricos foram coletados a partir do exame retrospectivo dos prontuários individuais, durante o período de janeiro de 1988 a dezembro de 1991, época em que foi desenvolvido um programa específico de atenção ao adolescente. O perfil encontrado possibilitou a discussão em torno das condições de existência e manifestações do processo saúdedoença, permitindo concluir pela necessidade de se superar o paradigma biologizante, a fim de contemplar as demais dimensões da vida do adolescente que interferem na dinâmica do seu processo saúde-doença.

UNITERMOS: adolescente, perfil saúde-doença, assistência

\section{INTRODUÇÃO}

Enquanto uma etapa do desenvolvimento humano a adolescência tem sido com freqüência pensada de forma a universalizar os fenômenos que a caracterizam 0 que acaba por reduzi-la às transformações da puberdade quando muito à versão psicologizada de tais fenômenos associando-as à noção de "crise".

Mesmo na perspectiva do Programa da Assistência Integral à Saúde do Adolescente (BRASIL, 1989), a adolescência assume, no dizer de AYRES (1994), o estatuto de um conceito integrador que propõe compreender $e$, conseqüentemente, intervir sobre cada indivíduo adolescente imputando-lhe atributos derivados de estudos que o tomam sob diferentes perspectivas: biológica, psicológica, sociológica, epidemiológica, antropológica entre tantas. À integridade de abordagem preconizada pelo Programa seria, portanto, derivada justamente da justaposição dessas tantas perspectivas, pressupondoas complementares e mutuamente potencializadoras. Se tal pressuposto estimula a interdisciplinaridade, no que se constitui em avanço, tem como contrapartida a "desubjetivação do sujeito adolescente, por meio da atribuição de uma identidade potencial e abstratamente construída na articulação de construções teóricas de naturezas diversas em que a dimensão biológica, a mais objetivamente apreensível e manuseável pelas rotinas dos serviços de saúde tal como normalmente organizados, passa a ser na prática uma espécie de procuradora das demais nos processos concretos de trabalho" (AYRES, 1994).

Contraditoriamente, embora as práticas assistenciais de saúde voltada para os adolescentes se orientem predominantemente para agravos de origem biológica, o perfil de mortalidade desse grupo populacional evidencia uma causa marcadamente extra-biológica, com predominância de causas externas (LOLIO et al. 1990; YUNES \& PRIMO, 1985) o que poderia em parte explicar a inadequação dessas práticas em transformá-lo. AYRES (1990) chega mesmo a afirmar que o pouco impacto dessas práticas sobre as condições devida e saúde das populações adolescentes acaba por negar as finalidades que as justificam. Dado que a adolescência “... intersecciona, mas não se restringe aos limites do corpo, do natural (...) expressando-se relativamente pouco em agravos orgânicos", o biológico não deveria ser a dimensão dominante na intervenção. Ainda assim, a assistência ao adolescente nos serviços de saúde, quando existe, centra-se fundamentalmente nos fenômenos de crescimentos e desenvolvimento, utilizando os

\footnotetext{
* Professor Assistente do Departamento de Enfermagem em Saúde Coletiva da Escola de Enfermagem da Universidade de São Paulo ** Professora Livre-Docente do Departamento de Enfermagem em Saúde Coletiva da Escola de Enfermagem da Universidade de São Paulo

*** Médica Pediatra da Administração Regional de Perituba-PE - ARS - 8
} 
instrumentos tradicionais das práticas institucionais de saúde, daí seu poder de interferência limitado sobre os perfis de morbi-mortalidade.

Buscando contribuir para a superação (no sentido diaLético do termo) dessa perspectiva, este trabalho se propõe a realizar uma aproximação do processo saúde/ doença do adolescente, enquanto objeto de trabalho em saúde, que permita interrogar o paradigma assistencial vigente, tendo como horizonte a construção de uma nova racionalidade para orientaras intervenções de enfermagem sobre o coletivo. Para tanto, foram propostos os seguintes objetivos:

- conhecer o perfil de saúde/doença dos adolescentes atendidos em uma unidade assistencial de saúde e explicá-lo, buscando estabelecer sua relação com as condições concretas de vida dessa clientela;

- interpretar esse perfil à luz da determinação social do processo saúde-doença.

\section{CAMINHO METODOLÓGICO}

\subsection{O Cenário do Estudo ****}

Esta investigação foi desenvolvida em uma das unidades assistenciais da Administração Regional de Pirituba/Perus (ARS-8) do Município de São Paulo, onde, desde 1989, a Escola de Enfermagem da Universidade de São Paulo desenvolve as atividades do Projeto de Integração Docente Assistencial que mantém com a Secretaria Municipal de Saúde de São Paulo.

O Município de São Paulo concentra 30,5\% da população do Estado o que, em 1991, equivalia a um contingente de 9,63 milhões de pessoas. A ARS-8, por sua vez, resulta da sua divisão em 10 regiões e seus respectivos Distritos de Saúde, ocorrida em 1989. Situa-se na região noroeste da cidade, sua extensão territorial é de $116,4 \mathrm{Km}^{2}$, sendo integrada por 2 distritos sanitários:

Pirituba e Perus. O primeiro compreende os distritos de Paz de São Domingos e Pirituba e o de Perus, os de Perus, Anhanguera e Jaraguá.

A população da região, de acordo com o censo de 1991, era de 224.585 habitantes (FUNDAÇÃO IBGE, 1991), sendo maior a concentração populacional nos distritos de Paz de Pirituba e Jaraguá. Característica das populações das áreas menos desenvolvidas, a pirâmide populacional da região tem base larga e ápice estreito, sendo que os menores de 15 anos representam 37,85\% do total. O índice de alfabetização é de 84,7\%, semelhante aos das demais regiões do Município de São Paulo.

Trata-se de um núcleo de ocupação antiga, com predomínio de residências horizontais, sendo que tem aumentado o número de núcleos favelados dispersos por toda a região. Não há dados oficiais sobre as redes de água e esgoto; no entanto, sabe-se que nas áreas centrais dos distritos a maioria dos domicílios é servida por água de rede pública, o mesmo não se podendo dizer sobre o esgoto sanitário, principalmente em Jaraguá e Perus.

E uma das regiões de mais baixa renda do município já que, do total da população, 55\% recebe até 5 salários mínimos por mês. A análise dos dados de mortalidade permite observar um número elevado de mortes por lesões ao nascer e outras causas perinatais, traduzindo uma assistência precária ao parto. Tal fato é bastante compreensível, já que na região há apenas 20 leitos para maternidade, obrigando as parturientes a se deslocarem para bairros vizinhos sem qualquer garantia de atendimento.

As condições precárias de vida se manifestam no grande contingente de óbitos por doenças infecciosas, destacando-se entre elas a pneumonia, enquanto que a mortalidade por causas externas, violentas em sua maioria (homicídios e acidentes de trânsito), traduz a tensão social característica dos grandes centros urbanos. Por outro lado, o que se denomina "urbanização sociopática" das grandes cidades dos países em desenvolvimento se expressa também nas mortes por doenças crônicodegenerativas, como os distúrbios cardiovasculares e as neoplasias. O diagnóstico de saúde realizado não apresenta dados relativos aos adolescentes.

Dentre os equipamentos municipais de prestação de assistência à saúde, a ARS-8 dispõe de 08 Unidades Básicas de Saúde (UBS), 02 Ambulatórios Especializados, 01 Hospital-Dia, 01 Centro de Convivência e Cooperativa, 01 Hospital Público Municipal de 55 leitos, distribuídos pelas áreas de Pediatria, Clínica Médica, Clínica Cirúrgica e Ginecologia, e 02 Unidades de Atendimento de Urgência. Existem ainda 01 Hospital Psiquiátrico de 230 leitos e 01 Hospital Geral de 120 leitos subordinados à Administração Estadual e também uma Casa de Repouso particular com 170 leitos.

\subsection{A assistência à saúde do adolescente}

A UBS Moinho Velho, localizada no distrito de Paz de Pirituba, foi uma das poucas unidades básicas da rede municipal de saúde a desenvolver uma forma sistematizada de assistência à saúde ao adolescente, muito embora essa sistematização tenha sido implantada sob a forma de um projeto-piloto, levado a cabo por iniciativa da equipe de saúde da própria UBS, capitaneada por uma médica pediatra, e a unidade não tenha se

*** Todos os dados aqui referidos baseiam-se no Diagnóstico de Saúde de Pirituba/Perus (ARS-8), realizado em 1989 e no relatório Municipalização da Saúde na Administração Regional Pirituba/Perus (ARS-8), de 1993 
constituído em referência para o atendimento aos adolescentes na região.

Essa assistência, tal como praticada na UBS Moinho Velho, consistia basicamente de atendimento médico à clientela de 12 a 19 anos. Observa-se que a faixa etária alvo não coincide com o critério cronológico estabelecido pela Organização Mundial da Saúde para caracterizar a adolescência, que é dos 10 aos 19 anos de idade, inclusive. Isso ocorre porque as faixas etárias compreendidas até os 11 anos completos se constituem em objeto de atenção da área da programação municipal genericamente denominada Saúde da Criança.

Centrava-se na atenção médica individual, visando dar suporte a esse grupo no que diz respeito a finalização do desenvolvimento pondero-estatural e ao amadurecimento sexual. Seu objetivo era o de acompanhar a curva de crescimento e o ganho ponderal de todos os clientes matriculados, com finalidade de conhecer seu padrão de crescimento e avaliar seu desenvolvimento. Buscava ainda intervir nos processos mórbidos dessa clientela através do diagnóstico médico e da instituição da terapêutica.

Consistia na consulta médica individual, compreendendo uma anamnese detalhada, diagnóstico e tratamento. Eram solicitados como exames laboratoriais de rotina o protoparasitológico de fezes, o exame de urina e o hemograma. A entrevista individual como adolescente era seguida de uma outra, com seus pais ou responsáveis, também realizada pelo médico. Os retornos eram agendados anualmente para os adolescentes púberes considerados saudáveis e semestralmente para os impúberes, a fim de realizar acompanhamento dos fenômenos ligados à puberdade.

Além do atendimento médico individualizado, o cliente era encaminhado para participar do Grupo de Adolescentes, orientado pelo médico, pelo psicólogo e, eventualmente, pela enfermeira. As discussões em grupo centravam-se em temáticas específicas, em geral relativas à sexualidade, ao conhecimento do corpo, à gravidez e à anticoncepção.

Essas atividades voltavam-se exclusivamente para a demanda efetiva da UBS, ou seja, para aquela clientela que comparecia espontaneamente ao serviço para atendimentos eventuais, ou então era egressa do programa de assistência à criança da UBS, caso em que o encaminhamento era feito pelos pediatras. A ocorrência de gravidez nas adolescentes se constituía em um dreno para a área de assistência à saúde da mulher.

Dado que a proposta de trabalho não era claramente definida e que subsistia às custas da iniciativa e do esforço pessoal de alguns profissionais, a adolescência não se colocou como objeto de intervenção para o conjunto dos trabalhadores da unidade, de forma que havia uma tendência para a não-adesão e para a não-atração da clientela-alvo. Assim, a demanda efetiva pode não ser o indicador mais adequado para se estimar qual seria a demanda potencial para essa área de atuação.

Havia e há pouca informação quantitativa e qualitativa sobre as necessidades específicas da população-alvo, uma vez que o serviço não mantinha formas de registro e avaliação sistemática das atividades que realizava nessa área. Ademais, uma vez que a Secretaria Municipal de Saúde não havia tomado para si a tarefa de implantar a assistência à saúde voltada para esse grupo populacional, as atividades realizadas na UBS Moinho Velho somente perduraram enquanto lá permaneceram os profissionais efetivamente envolvidos com o trabalho. A transferência desses profissionais para outras unidades, no final de 1992, pôs fim a essa tentativa de sistematização.

Hoje, a principal forma de contato dos adolescentes com o serviço continua sendo a assistência médica de urgência, em particular o prontoatendimento, já que a racionalidade dominante nos serviços de saúde é aquela associada ao trabalho de base clínica.

\subsection{Etapas de trabalho}

A caracterização da clientela inscrita no Serviço de Atendimento ao Adolescente da UBS Moinho Velho foi feita através do estudo retrospectivo dos prontuários daqueles que passaram por consulta médica de matrícula no período de janeiro de 1988 a dezembro de 1991.

A despeito das dificuldades encontradas, tais como a impossibilidade de localizar $13 \%$ dos prontuários ou a existência de dados incompletos (19\%), a análise dos 104 prontuários permitiu evidenciar o perfil dos adolescentes no que toca a: sexo, idade, composição familiar, trabalho, escolaridade, freqüência à escola e adequação série/idade. Foi possível ainda agregar informações relativas à situação vacinal, dados antropométricos traduzidos em percentis de peso e altura, idade da menarca para as adolescentes do sexo feminino, queixas principais que motivaram 0 comparecimento ao serviço e o diagnóstico médico subseqüente.

\section{RESULTADOS E DISCUSSÃO}

No período compreendido entre janeiro de 1988 e dezembro de 1991, inscreveram-se no programa 155 adolescentes, conforme consta no livro de matrículas. Não foram encontrados 21 prontuários. Verificados os demais 134, foi possível localizar a "Ficha de Matrícula", base da coleta de dados, em apenas 104. Portanto, a análise retrospectiva já mencionada refere-se a esses últimos. 


\subsection{Condições de existência}

Constatou-se que foram realizados 805 atendimentos a essa clientela, incluídos aí tanto os 365 atendimentos em grupo como as 440 consultas individuais especializadas (médicas, odontológicas, psicológicas), numa média de 4,3 consultas por adolescente. Dos inscritos, 62 eram do sexo feminino e 42 do masculino, a maioria com idade entre 12 e 15 anos.

Excetuando-se a faixa dos 14 aos 15 anos, em todas as demais houve predominância do sexo feminino. CHIPKEVITCH et ai (1989), descrevendo a população adolescente por eles atendida no ambulatório de um hospital infantil, nos anos de 1982 a 1987, também constataram o predomínio de usuárias do sexo feminino, atribuindo o fato não só ao número ligeiramente superior $(50,5 \%)$ de adolescentes do sexo feminino na população total de adolescentes no Brasil, mas também às influências "entre os papéis e as características sexuais do homem e da mulher, determinadas por influências biológicas, culturais e sociais e que levam a diferentes padrões de morbidade, de expressão elou valorização dos sintomas, de preocupação com a saúde, de inserção no mercado de trabalho e de disponibilidade de tempo para procurar serviços médicos". De um modo geral, a intervenção à saúde tem se voltado muito mais para o corpo feminino que para o masculino, especialmente por sua associação com a reprodução e o cuidado com a prole. Para esses mesmos autores, a procura dos serviços por adolescentes mais jovens, principalmente, resulta do fato de que estes, ao experimentarem as intensas modificações decorrentes do processo pubertário, manifestam-nas sob a forma de sintomas e preocupações que afetam inclusive a família.

No caso específico do serviço de atendimento ao adolescente da UBS Moinho Velho, a maior concentração da demanda na faixa dos 12 aos 15 anos parece decorrer da forma de organização do atendimento médico - já que a clientela até os 11 anos de idade é em geral absorvida pela área programática da Saúde da Criança. Ainda assim, três pacientes do sexo feminino e dois do sexo masculino, na faixa etária dos 11 aos 12 anos, foram inscritos no serviço.

Esses adolescentes provinham em sua grande maioria (86\%) do Estado de São Paulo e destes, todos eram da Capital, sendo que $77 \%$ integravam famílias constituídas por pelo menos um dos cônjuges e seus filhos; $6 \%$ integravam famílias que incluíam outros parentes além dos pais e irmãos e outros residiam com outras famílias que não a própria, na condição de agregados.

De fato, o padrão familiar dominante no Brasil ainda é o da família conjugal, aquela composta pelo casal e seus filhos, de modo que em 1990, 83,9\% das crianças e adolescentes de zero a 17 anos de idade provinham dessas famílias (SILVA, 1992). Desde 1981, entretanto, dados obtidos pela Pesquisa Nacional de Amostra de Domicílios (PNAD) deixavam antever o progressivo aumento daquelas famílias chefiadas por mulheres (SILVA, 1987), a par de outra tendência marcante, a diminuição do tamanho médio das famílias. Essas famílias monoparentais, compostas principalmente pela mulher e seus filhos, aumentaram em todos os níveis de renda e ainda mais em extratos de renda mais alta, atingindo um incremento de $208 \%$ na faixa superiora 3 salários mínimos. Mesmo assim, ainda é entre as famílias mais pobres onde esse arranjo é mais freqüente, cerca de $20 \%$ daquelas com rendimentos até $1 / 2$ salário mínimo. Justamente nessas famílias a ausência de um dos cônjuges e, conseqüentemente, de sua remuneração, representa um agravamento das condições já precárias de existência, com repercussões sobre o crescimento e o desenvolvimento dos filhos, em especial se estes são menores de 14 anos e, portanto, estão impedidos por lei de exercer trabalho remunerado. Nesses casos, cabe à mulher arcar com o sustento de toda a família, sobrepondo ao trabalho doméstico jornadas intensas e freqüentemente mal remuneradas, tanto em decorrência de sua pouca qualificação para competir no mercado de trabalho como da subalternidade de gênero a que está exposta. E justamente nessas famílias que 0 ingresso dos adolescentes no mercado de trabalho, mesmo aqueles muito jovens, se faz precocemente, aumentando a tendência de abandono da escola (SILVA, 1992).

$\mathrm{Na}$ população estudada, poucos exerciam trabalho remunerado (10\%) e os que o faziam tinham mais que 15 anos de idade.

Ao contrário do encontrado neste estudo, no Brasil, no ano de 1990, as crianças e adolescentes trabalhadores de 10 a 17 anos de idade representavam $11,6 \%$ da população economicamente ativa no Brasil no ano de 1990 - um contingente de 7,5 milhões de pessoas. A maioria havia ingressado no mercado de trabalho para garantir a sobrevivência familiar. Em famílias com renda inferior a 1/2 salário mínimo, a taxa de atividade (relação entre o total de pessoas economicamente ativas e a população total) na faixa dos 10 a 14 anos era de $22,7 \%$, caindo para $4,4 \%$ quando a renda familiar superava os 2 salários mínimos (SILVA, 1992).

Se, por um lado, a inserção formal das crianças e dos adolescentes no mundo do trabalho representa a possibilidade de melhoria do padrão de subsistência do núcleo familiar, nem por isso ela deixa de ser problemática, já que freqüentemente se dá às custas da interrupção da atividade escolar e, portanto, do processo de qualificação que permitiria um ingresso mais favorável em época futura. Pó conseguinte, são esses os grupos que enfrentam as maiores taxas de desemprego e subemprego, especialmente nos momentos de agudização das crises 
econômicas. Embora o trabalho seja legalmente permitido apenas para os maiores de 14 anos, dentre os adolescentes brasileiros trabalhadores na faixa etária dos 10 aos 14 anos de idade, no ano de 1990, 47,4\% tinham algum tipo de vínculo empregatício com um empregador, enquanto que outros $47,6 \%$ estavam na condição de trabalhadores não remunerados, ajudando os familiares em atividades econômicas. No grupo dos 15 aos 17 anos, $72,1 \%$ dos adolescentes trabalhadores possuíam um empregador, ainda que apenas $32 \%$ tivessem a carteira assinada. Freqüentemente enfrentavam jornadas diárias de oito horas ou mais, tendo como contrapartida o salário mínimo ( $96,3 \%$ dos que tinham entre 10 e 14 anos e $81 \%$ dos 15 aos 17 anos), fruto de sua pouca qualificação e do baixo nível de instrução (SILVA, 1992).

Quanto à escolaridade, quase todos os adolescentes que haviam comparecido à consulta médica de matrícula no Programa de Adolescentes da UBS ainda freqüentavam a escola (91\%).

A década de 80 assistiu à expansão do número de crianças brasileiras matriculadas no sistema formal de ensino fundamental obrigatório, orientado para 0 atendimento das crianças e adolescentes dos 7 aos 14 anos e organizado sob a forma de oito séries anuais. A despeito desse crescimento, a década de 90 iniciou-se com um contingente de aproximadamente 4 milhões de crianças e adolescentes excluídos do sistema escolar. Também as oportunidades de acesso e permanência na escola apresentam profundas desigualdades para os diferentes grupos sociais. Em 1990, a porcentagem de filhos de 7 a 14 anos oriundos de famílias que recebiam acima de 2 salários mínimos e que freqüentava a escola era de $97 \%$, reduzindo-se para $74,5 \%$ quando o rendimento familiar máximo não ultrapassava $1 / 2$ salário mínimo (SILVA, 1992).

No Brasil, a análise da distribuição da população jovem (0-17 anos) por faixa etária permite verificar que, no ano de 1987, 18,6\% encontravam-se entre os 7 e 14 anos, período de escolaridade obrigatória. Desses, 8 $3,2 \%$ estavam matriculados em escolas. O valor máximo da taxa de escolarização era atingido por crianças de 10 anos de idade, iniciando a partir daí um declínio progressivo que se acentuava por volta dos 14 anos, o que coincide com o limite final de idade em que há obrigatoriedade da escolarização. Aos 17 anos, essa taxa estava reduzida a 44,2\% (SILVA, 1987). Também a expansão das matrículas a que se referiu não se deu da mesma forma em todas as faixas etárias. Em 1989, entre os 7 e os 10 anos, $85 \%$ das crianças e adolescentes freqüentavam a escola, enquanto que na faixa etária dos 15 aos 17 anos essa cifra não ultrapassava os $55 \%$ (SABOIA, 1989).

Com relação à repetência escolar, cerca de $48 \%$ dos adolescentes estudados que freqüentavam a escola haviam sido reprovados pelo menos uma vez.
No Brasil, a taxa média de repetência, representada pela porcentagem de alunos reprovados em uma determinada série em relação à matrícula total da série no mesmo ano letivo, manteve-se em $20 \%$ ao longo da década de 80 (SILVA, 1992). Do ponto de vista da repetência, a $1^{\text {a }}$ série do $1^{\circ}$ grau era um ano crítico, sendo maior do que a média em todas as demais séries do $1^{\circ}$ grau. No Estado de São Paulo, essa taxa foi de $28,2 \%$ em 1984, porém, com a instituição da promoção automática da primeira para a segunda série, caiu para 3,6\% em 1985 (SILVA, 1987), o que deslocou para a $2^{a}$ série as maiores taxas de repetência (SILVA, 1992).

Os índices elevados de repetência, de certa forma, são um dos indicadores da qualidade do ensino e seu impacto atenua os benefícios representados pelos aumentos que vêm sendo constatados na taxa de escolarização. Constituem também um dos fatores que mais induzem ao abandono dos estudos, com a exclusão definitiva do aluno do sistema de ensino formal. A taxa de evasão imediata, representada pela porcentagem de alunos que abandona uma determinada série em relação ao número total de matrículas nessa mesma série e durante o mesmo ano letivo, no Brasil nos anos 80 foi da ordem de $13 \%$ (SILVA, 1992). Essa evasão é mais expressiva na primeira (24\%) e na quinta (19\%) séries do $1^{\circ}$ grau e, nas escolas da rede pública, é duas vezes superior em relação às particulares (SILVA, 1987).

Os dados disponíveis para a década de 80 evidenciam que apenas $20 \%$ dos matriculados na $1^{\text {a }}$ série do $1^{\circ}$ grau concluíam a $8^{\mathrm{a}}$ série, que da $1^{\mathrm{a}}$ para a $2^{\mathrm{a}}$ séries perdiam-se $40 \%$ dos alunos e que à $4^{\mathrm{a}}$ série chegavam apenas $48 \%$. Os alunos abandonavam o sistema escolar tendo concluído em média 3,7 séries, o que é considerado insuficiente para tornar irreversível a alfabetização (SILVA, 1992).

Com relação à adequação série/idade, esta ocorria em $45 \%$ dos casos estudados, havendo atraso escolar em $44 \%$.

Também a correspondência ideal entre série e idade ao longo do percurso escolar, a partir do ingresso aos 7 anos, fundamenta-se na temporal idade esperada no desenvolvimento da capacidade de aprendizado das crianças e adolescentes de modo que a inadequação série/ idade repercute sobre o rendimento escolar, podendo se constituir ainda numa fonte de desestímulo e de desadaptação, concorrendo para a evasão escolar. Decorre principalmente do ingresso tardio e da repetência escolar. Em 1990, das crianças brasileiras matriculadas na $2^{\mathrm{a}}$ série do primeiro grau, $62,8 \%$ tinham mais de 8 anos. $O$ atraso vai se acumulando com a idade: no mesmo ano, $80 \%$ dos adolescentes com mais de 14 anos que freqüentavam a escola apresentavam algum tipo de atraso com relação à série em que estavam matriculados (SILVA, 1992). 


\subsection{Manifestações do processo saúde-doença}

$\mathrm{Na}$ consulta de matrícula, comprovaram haver completado o esquema vacinal da infância $28 \%$ dos inscritos no programa. Saliente-se que para essa comprovação era necessária a apresentação da carteira de vacinação, que a maioria não portava. Nas consultas subseqüentes, aqueles que efetivamente não conseguiam comprovar ter completado o esquema vacinal básico eram encaminhados para vacinação.

Da mesma forma, mais da metade da clientela adolescente atendida por CHIPKEVITCH et al. (1989) no ambulatório do Serviço Social do Hospital Infantil Darcy Vargas, em São Paulo, entre outubro de 1992 e março de 1987, estava com o esquema vacinal atrasado, situação semelhante à que já havia sido constatada por COLLI et al. (1984). Na ocasião, aquelas autoras já enfatizavam a necessidade de intensificação da vacinação de adolescentes, uma vez que os programas de imunização estão voltados prioritariamente para crianças menores de 5 anos, o que diminui a exposição da população em geral aos agentes infecciosos das doenças preveníveis por imunização. Assim sendo, adolescentes e adultos jovens, se não adequadamente vacinados, podem constituir um grupo expressivo de susceptíveis.

Em 1973, foi instituído no Brasil o Programa Nacional de Imunizações (PNI) integrando o Programa Ampliado de Imunizações (PAI) da Organização PanAmericana de Saúde. Criado para integrar e coordenar as atividades de vacinação que até então vinham sendo desenvolvidas no Brasil, tem como principal objetivo "contribuir para o controle ou erradicação da poliomielite, do sarampo, da difteria, do tétano, da coqueluche e subsidiariamente da tuberculose, mediante a imunização sistemática da população exposta a essas doenças". Sua meta operacional básica é a vacinação de 100\% dos menores de um ano com todas as vacinas que constam do esquema básico: vacina contra a tuberculose (BCG), vacina oral contra a poliomielite, vacina tríplice bacteriana (contra a difteria, o tétano e a coqueluche), vacina contra o sarampo e vacina tríplice viral (contra o sarampo, rubéola e caxumba, esta aplicada exclusivamente nos estados de São Paulo e Paraná) (BRASIL, 1993).

Para o alcance dessa meta, a partir de 1980 o PNI passou a preconizar, além da vacinação rotineira na rede de unidades básicas de saúde, a realização dos Dias Nacionais de Vacinação para a administração da vacina oral contra a poliomielite, o que elevou a $90 \%$ a cobertura para essa vacina, sucesso que determinou a eliminação ao poliovírus selvagem no país, desde 1989 (BRASIL, 1993).

À época da criação do $\mathrm{PNI}$, apenas uma pequena parte das crianças brasileiras era vacinada. Por volta de 1980, ainda a metade daquelas que tinham 1 ano de idade não completara o esquema básico. Em 1990, foram instituídos os dias nacionais de multivacinação para aumentar a cobertura vacinal para as demais vacinas cuja média, até 1991, ficava em torno dos 75\% (SILVA, 1992).

A despeito da eficácia, do baixo custo e d segurança da vacinação como um dos instrumentos no controle das doenças transmissíveis, muito há para ser feito para que sejam atingidos $100 \%$ das crianças nascidas a cada ano. Entre essas medidas incluem-se a melhoria da distribuição da rede de serviço e a qualificação técnica e administrativa dos trabalhadores, a ampliação dos horários de atendimento, a redução das oportunidades perdidas para a vacinação e o aperfeiçoamento dos sistemas administrativos de apoio, suprimento e programação (BRASIL, 1993).

Os dados antropométricos apresentados da clientela analisada permitiram situar entre a maior parte dos adolescentes os percentis 10 e 90, portanto dentro da normalidade: $74 \%$ para peso e $69 \%$ para altura.

Segundo MARCONDES (1982) os percentis são pontos estimativos de uma distribuição de freqüência que determinam uma dada porcentagem de indivíduos que se localizam abaixo ou acima deles "(...) informam sobre a posição de um indivíduo em relação à população pertencente e sobre a probabilidade de pertencer a um universo normal ou patológico". Os percentis permitem, por exemplo, classificar a severidade da desnutrição (diagnosticada em função de dados clínicos - anamnese alimentar e exame físico) em graus, sendo considerados desnutridos leves as crianças e os adolescentes cujo peso se situe entre os percentis 2,0 e 2,5 e desnutridos graves aqueles que apresentem sinais clínicos de desnutrição e peso abaixo do percentil 2,5. Entretanto, o percentil de peso só se constitui em indicador adequado do grau de deficiência nutricional se a estatura for normal para a idade, ou seja, situada entre os percentis 2,5 e 97,5 . Para aqueles cuja estatura situa-se abaixo do percentil 2,5 é apropriado falar em baixa estatura, assim como o é falar em alta estatura para os que estiverem acima do percentil 97,5 . Alturas situadas entre os percentis 2,5 e 10 e entre 90 e 97,5 caracterizam situações que requerem vigilância para a baixa e a alta estaturas, respectivamente.

Nas adolescentes do sexo feminino a idade da menarca situou-se entre os 11 e 14 anos, com pico nos 13 anos de idade.

A antecipação da idade da menarca é um fenômeno que se tem feito notar desde o início deste século. Segundo a Organização Pan-americana da Saúde (OPAS), na Inglaterra a idade média da menarca caiu de 14 para 12,9 anos no período de 1900 a 1960. Em outros países, essa redução operou-se ainda mais rapidamente: na Nigéria essa média antecipouse de 14 para os 13 anos de 1960 ao final de 1970 , chegando a atingir os 12,3 anos nos grupos sócioeconômicos mais favorecidos. (OPAS, 1988). Em 
1988, Colli apud GOLDBERG (1991) verificou que a idade da menarca entre adolescentes brasileiras situava-se próxima aos 12,2 anos e que o início da puberdade podia ser localizado por volta dos 9,3 no sexo feminino e 10,3 no sexo masculino.

Como se pode verificar no gráfico abaixo (Figura 1), a maioria dos adolescentes atendidos havia comparecido à consulta acompanhada da mãe, cuja queixa principal dizia respeito ao comportamento e desempenho escolar dos filhos. Estes, por sua vez, em grande parte não referiam queixas. Verifica-se, portanto, uma predominância de manifestações extrabiológicas do processo saúde-doença, próprios da esfera da saúde mental.

Figura1 - Comparação entre as queixas dos adolescentes atendidos e de seus pais

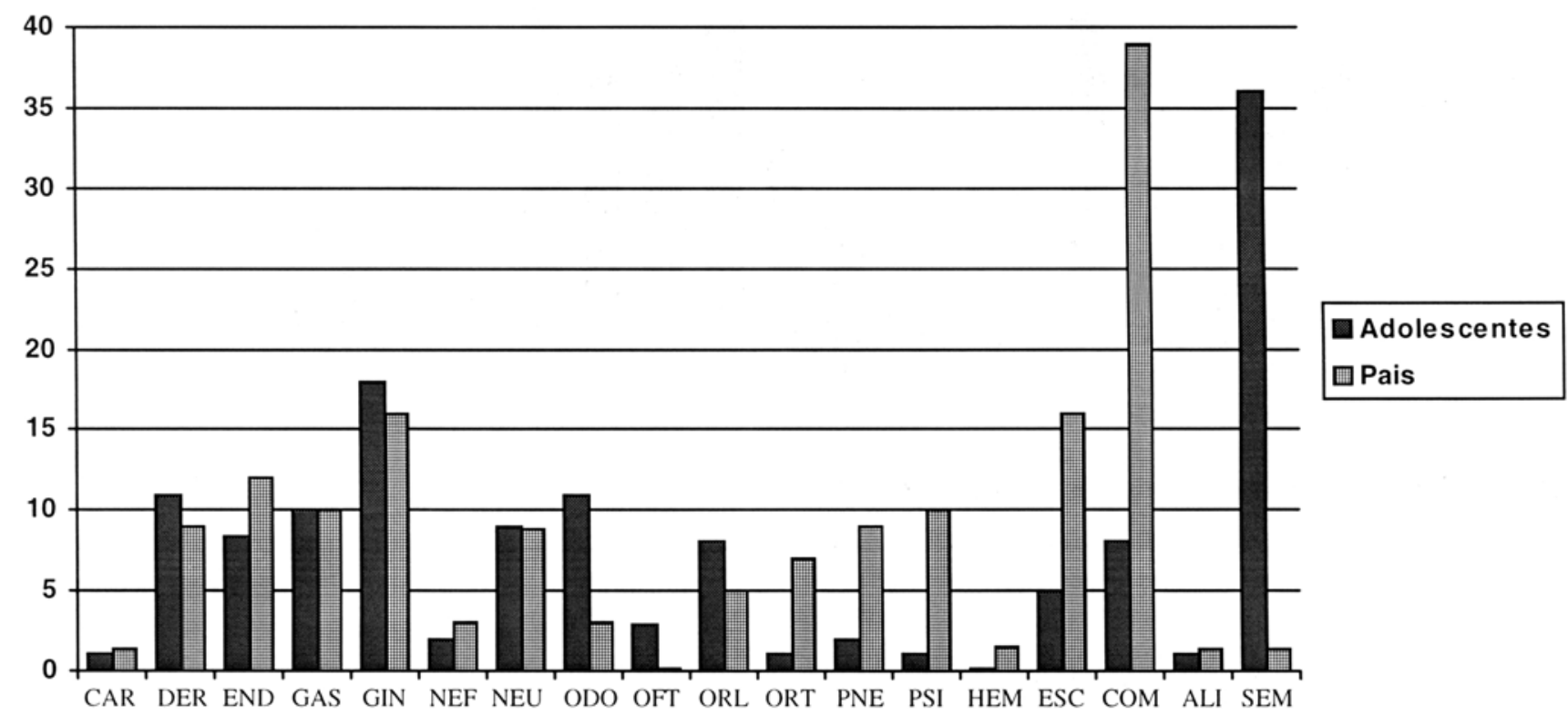

Natureza da queixa

\begin{tabular}{|llll|}
\hline LEGENDA & & \\
CAR & Queixas cardíacas & DER & Queixas dermatológicas \\
END & Queixas endocrinológicas & GAS & Queixas gástricas \\
GIN & Queixas ginecológicas & NEF & Queixas nefrológicas \\
NEU & Queixas neurológicas & ODO & Queixas odontológicas \\
OFT & Queixas oftalmológicas & ORL & Queixas otorrinolaringológicas \\
ORT & Queixas ortopédicas & PNE & Queixas pneumológicas \\
PSI & Queixas psicológicas & HEM & Queixas hematológicas \\
ESC & Problemas na escola & COM & Problemas de comportamento \\
ALI & Problemas alimentares & SEM & Sem queixas \\
\hline
\end{tabular}

Existia concordância entre as queixas dos pais e dos adolescentes quando estas se referiam a problemas dermatológicos, endocrinológicos, ginecológicos, nefrológicos e neurológicos. Quanto as demais, constata-se que a percepção do adolescente a respeito de seu processo saúdedoença diferia da de seus pais. Estes, por sua vez, quando identificavam "problemas de conduta" em seus filhos, buscavam a solução para tais conflitos na autoridade médica, "biologizando-os".

Os diagnósticos médicos sumarizados na Figura 2 revelaram predominância de problemas de ordem odontológica, ortopédica, ginecológica e dermatológica. 


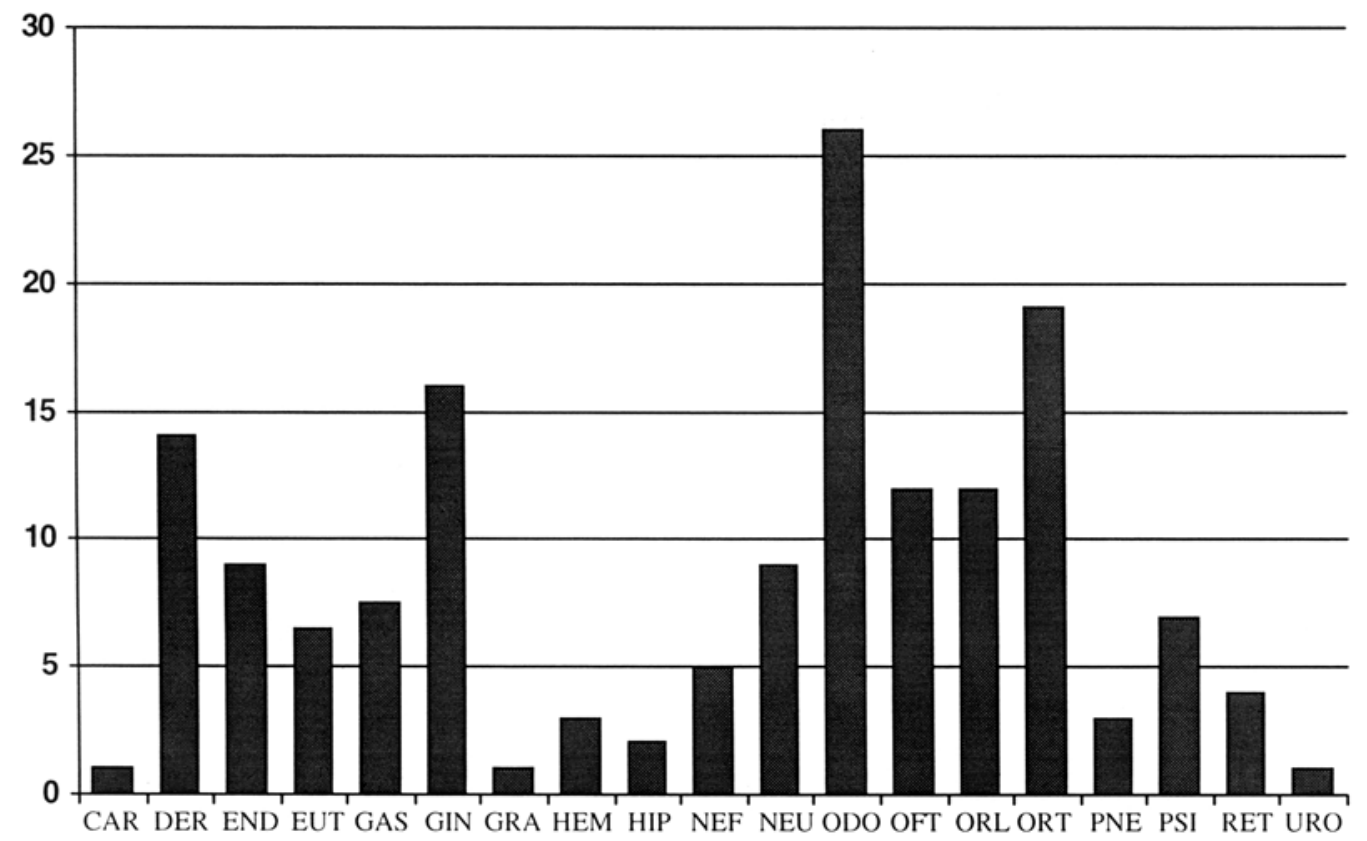

Diagnósticos

Figura 2 - Diagnósticos médicos dos adolescentes atendidos

\begin{tabular}{|llll|}
\hline LEGENDA & & \\
CAR & Distúrbios cardíacos & DER & Distúrbios dermatológicos \\
END & Distúrbios endocrinológicos & EUT & Eutropia \\
GAS & Distúrbios gastro-intestinais & GIN & Distúrbios ginecológicos \\
GRA & Gravidez & HEM & Distúrbios hematológicos \\
HIP & Hipertensão & NEF & Distúrbios nefrológicos \\
NEU & Distúrbios neurológicos & ODO & Problemas odontológicos \\
ORL & Distúrbios otorrinolaringológicos & ORT & Distúrbios ortopédicos \\
PNE & Distúrbios pneumológicos & PSI & Distúrbios psicológicos \\
URO & Distúrbios urológicos & RET & Retornos \\
\hline
\end{tabular}

A experiência de CHIPKEVITCHE et al. (1989), no atendimento ambulatorial a 516 adolescentes no Hospital Infantil Darcy Vargas, em São Paulo, no período de outubro de 1982 e março de 1987, resultou em 2.197 consultas, com 1927 diagnósticos. Dentre esses, os autores chamam a atenção para o lugar ocupado pelos denominados "distúrbios psicossociais", que incluíam entre os problemas mais freqüentes os distúrbios emocionais de conduta, distúrbios da dinâmica familiar e somatizações. Ressaltam que esse grupo de diagnósticos foi superado apenas pelas cáries, pelos problemas de pele e de otorrinolaringologia. Há que destacar ainda a correlação que estabeleceram entre os diagnóstico e as precárias condições de vida da clientela atendida.

No período de março de 1986 a março de 1991 o Programa de Atendimento Integral à Saúde do Adolescente do Estado de São Paulo contava com 45.392 inscritos, sendo 30.262 mulheres e 15.130 homens. Nos adolescentes do sexo masculino, entre os motivos mais freqüentes para a procura do serviço encontravam-se as preocupações relativas ao crescimento e ao desenvolvimento $(25,0 \%)$, as dores vagas $(24,1 \%)$, as queixas dermatológicas $(17,3 \%)$ e

digestivas $(13,9)$. Um número expressivo, porém, havia comparecido aos serviços sem queixas $(16,3 \%)$ ou para buscar informações (12,5\%). Já para o sexo feminino, as queixas ginecobstétricos (43,0\%), as preocupações com o crescimento e o desenvolvimento (18,6\%), as queixas dermatológicas $(13,5 \%)$, as tonturas $(12,9 \%)$ e os problemas digestivos $(12,3 \%)$ foram às causas mais freqüentes. Cerca de $10,6 \%$ não havia manifestado queixas na consulta de matrícula, enquanto que 9,3\% apenas procuravam informações. Para ambos os sexos, os motivos mais freqüentes para a demanda específica para o atendimento psicológico foram os distúrbios emocionais e os problemas escolares. Por sua vez, os diagnósticos mais freqüentes, por ordem, foram: problemas ginecobstétricos, odontológicos, psicológicos, familiares, escolares, parasitoses e os problemas de crescimento e desenvolvimento (SÃO PAULO, s.d.).

Quanto à clientela na faixa dos 10 aos 14 anos atendida em unidades ambulatoriais municipais no período de abril a junho de 1991, as causas mais freqüentes para a procura do serviço foram as doenças do aparelho respiratório (28,8\%), as lesões e os envenenamentos 
$(20,1 \%)$ e as doenças infecciosas e parasitárias $(13,5 \%)$. Entre os 15 e os 19 anos, em primeiro lugar apareceram as oportunidades de contato com os serviços de saúde (diagnóstico precoce de câncer cérvico-uterino, vacinação e pré-natal), representando $18,6 \%$ do total, seguidas pelas doenças do aparelho respiratório $(17,7 \%)$ e pelas lesões e envenenamentos (15\%) (CENTRO BRASILEIRO PARA A INFÂNCIA E A ADOLESCÊNCIA, 1993).

\section{CONSIDERAÇÕES FINAIS}

A caracterização que se procurou realizar com base nos dados disponíveis nas fichas de inscrição no Programa de Assistência ao Adolescente da UBS Moinho Velho, de certa forma, retrata o processo de trabalho operado na prática com esse segmento populacional. O faz certamente tornando estático, "congelando" algo que é dinâmico na sua natureza: a forma como os trabalhadores interpretam e intervêm nas necessidades expressas por esse grupo populacional e como o serviço responde às suas demandas específicas. É possível perceber que a intervenção no processo saúde-doença desses adolescentes está centrada na dimensão singular, resultando em produtos também singulares, já que se fundamenta nas consultas médica e psicológicas individuais.

Se, por um lado, o Programa de Assistência Integral ao Adolescente, tal como operado na UBS Moinho Velho nos anos de 1988 a 1992, representou uma tentativa pioneira de sistematização da assistência a esse grupo populacional no âmbito da Secretaria Municipal de Saúde de São Paulo, por outro, o modelo tecnológico empregado não foi capaz de superar a assistência médica individual, como forma privilegiada de intervenção. A utilização da idade como critério básico para a delimitação da populaçãoalvo do programa, acaba por se constituir em um denominador comum que encobre realidades de vida e saúde distintas. O trabalho de base clínica, utilizado como forma de intervenção no processo saúde-doença desses adolescentes, transforma demandas variadas e complexas em diagnósticos médicos ou, quando muito, em questões psicológicas.

Assim sendo, como traduzir a adolescência, na sua dimensão coletiva, em um objeto concreto (e concretamente manipulável) dentro do processo de trabalho em saúde? Como superaras limitações do modelo clínico, reorganizando o trabalho de forma a atender necessidades definidas no tecido social?

A apreensão da natureza social dos carecimentos dos adolescentes deve se dar a partir da experiência coletiva e, para isso, a atenção a eles dirigida precisa superar os limites dos corpos individuais na compreensão de seu processo saúde- doença, para que este se coloque para a assistência definido a partir de necessidades trans-individuais.

Para tanto, AYRES (1994) propõe a utilização de um conceito estratégico de adolescência, em substituição ao conceito integrador, a que se fez referência na Introdução. Trata-se, no dizer desse autor, de um "conceito rede", capaz de captar demandas de saúde associadas a processos concretos de adolescência e assim viabilizar formas alternativas de objetivação da saúde dos adolescentes. Nesse conceito estratégico, a idade deixaria de ser um recorte privilegiado do objeto adolescência, para se constituir em um dos elementos empíricos para a sua caracterização (e salienta AYRES: "não o único nem necessariamente o melhor"), assim como a inserção escolar e no trabalho, a composição familiar e a conjugalidade, a classe social, entre outros, que podem ser adotados, sempre provisoriamente e em função de suas possibilidades explicativas frente ao fenômeno concreto de "estar adolescendo", para indivíduos também concretos, histórica e socialmente determinados.

Assim, a intervenção voltar-se-ia para as necessidades definidas a partir dos perfis epidemiológicos de grupos homogêneos, tendo como horizonte não apenas a produção de serviços, mas também de saberes e instrumentos de intervenção cada vez mais adequados a essa finalidade. A consulta médica individual ficaria então reservada apenas para aquelas situações, específica sempre que fosse necessária.

Entretanto, ao propor uma alternativa de superação, AYRES (1994) alerta que o conceito estratégico, se levado ao extremo:

“... acaba por produzir a mesma de subjetivação que rejeitávamos na polaridade integradora. A conceituação estratégica, ao vincular-se a práticas que deslocam do espaço mais imediato da intervenção o critério que a orienta, tende a limitar as possibilidades de resistência dos indivíduos à aniquilação de sua subjetividade no processo de trabalho concretamente operado. Em outros termos, no pólo integrador a objetivação da adolescência restringe a condição de sujeito dos adolescentes por meio da naturalização da adolescência, mas abre espaço para o adolescente resistir à sua de subjetivação no momento operatório do trabalho, por instruir uma intervenção estruturalmente apoiada na particularidade do indivíduo, na relativa autonomia do sujeito adolescente identificar-se ou não com as necessidades trazidas para a intervenção. No pólo estratégico dá-se o inverso: procura-se 
resgatar a condição objetiva de sujeito do adolescente por meio de processos sociais concretos, mas a subjetividade desses indivíduos terá uma relação mediada com o processo de trabalho. A decisão a respeito das necessidades que justifica a intervenção programática estão dadas previamente às situações de intervenção.

As reflexões de SOUZA e KALICHMAN (1992) suscitam ainda outras questões: no processo saúdedoença de indivíduos, grupos ou comunidades, os serviços assistenciais de saúde, de maneira geral, têm concentrado sua atuação em apenas um dos pólos desse processo-o da doença.

Dessa forma, a promoção da saúde (especialmente importante em se tratando de adolescentes, cujas manifestações do processo saúde- doença não se evidenciam principalmente sob a forma de agravos orgânicos) exige pensá-la como um conceito positivo e não apenas como ausência de doença. Nesse e o de qualidade de vida, por eles definida como "...uma condição de existência dos homens, sempre referida ao modo de viver em sociedade, isto é, dentro dos limites que a cada momento histórico estão colocados para se viver o cotidiano", tendo como batizadores o grau de liberdade do cidadão e a sua capacidade de usufruto dos avanços técnicos e científicos da sociedade - o que "... equivale a estabelecer uma correspondência entre a idéia de cidadania e o direito de consumidor".

A ruptura, portanto, com as formas de intervenção historicamente determinadas sobre o pólo doença se daria justamente na capacidade de respostas desses serviços assistenciais às necessidades de saúde da população, ao invés do atendimento às demandas por cuidado na vigência da doença.

\section{TO BE ADOLESCENT AND TO BE ILL: THE HEALTH-ILLNESS PROFILE OF USERS OF BASIC HEALTH UNITS IN THE CITY OF SÃO PAULO}

The aim of the study is to verify the health-illness profile of adolescent users of a Basic Health Unit in the city of São Paulo (SP - Brazil). Empirical data were gathered through the retrospective analysis of individual reports, during the time in which a specific program for adolescents was developed, January 1988 to December 1991. The identified profile leads to a reflection concerning adolescents' life conditions and the correlated health-illness process expressions, enabling the conclusion that the biological paradigm must be surpassed so that other dimensions of the adolescents' existence that interfere in their health-illness process can be expressed

\section{ADOLECER Y ENFERMARSE: EL PERFIL DE SALUD-ENFERMEDAD DE USUARIOS DE UNA UNIDAD BÁSICA DE SALUD DE LA MUNICIPALIDAD DE SÃO PAULO}

El presente estudio tuvo la finalidad de caracterizar el perfil de salud-enfermedad de los adolescentes asistidos por una Unidad Básica de Salud de la Municipalidad de São Paulo (SP, Brasil). Las historias individuales se constituyeron en la fuente de los datos empíricos, en forma retrospectiva desde enero de 1988 hasta diciembre de 1991. Los resultados permitieron verificar las condiciones de existencia y las manifestaciones de los procesos de salud-enfermedad de la población. Además, permitieron visualizar la necesidad de superar el paradigma biologizante en el sentido de incluirse las demás dimensiones de la vida de los adolescentes que influencian en la dinámica de sus procesos de salud-enfermedad.

TÉRMINOS CLAVES: adolescente, perfil de salud-enfermedad, asistencia

\section{REFERÊNCIAS BIBLIOGRÁFICAS}

01. AYRES, J. R.. de C. M Adolescência e saúde coletiva: aspectos epistemológicos da abordagem programática. In: SCHRAIBER, L.B. (org.) Programação em saúde hoje. São Paulo: Hucitec, 1990. p. 139-82
02.

\section{práticas}

. Ação programática e renovação das prálicas saúde e 42, p. 54-8, 1994.

03. BRASIL. Ministério da Saúde. Secretaria Nacional de Programas Especiais de Saúde. Divisão Nacional de Saúde Materno Infantil. Programa de saúde do adolescente: bases programáticas. Brasília, 1989. 
04. . Ministério da Saúde. Fundação Nacional de Saúde. Programa nacional de imunizações: 20 anos. Brasília, 1993.

05. CENTRO BRASILEIRO PARA A INFÂNCIA E ADOLESCÊNCIA. Perfil da criança e do adolescente na cidade de São Paulo: diagnóstico social convênio 117. São Paulo: Instituto Lidas, 1993. /mimeografado/

06. CHIPKEVITCHE, E. et al. Experiência em atendimento ao adolescente em um ambulatório hospitalar da rede pública. J.Pediatr., v. 65, n. 4, p. 103-13, 1989.

07. COLLI, A.S. et al. Vacinação de adolescentes em atendimento ambulatorial. Pediatria, v. 6, n. 4/6, p. 189-91, 1984.

08. FUNDAÇÃO INSTITUTO BRASILEIRO DE GEOGRAFIA E ESTATÍSTICA - IBGE. Censo Demográfico 1991: resultados do universo relativo às características da população e dos domicílios. Rio de Janeiro: IBGE, 1991. (São Paulo, n. 21)

09. GOLDBERG, T.B.L. et al. Avaliação do desenvolvimento afetivo social do adolescente na faixa etária dos 15 aos 18 anos: estudo com adolescentes do município de Botucatu - SP - aspectos da sexualidade. J.Pediatr., v. 70, n. 1, p. 39-43, 1991.

10. LOLIO, C. A. de et al. Mortalidade de adolescentes no Brasil, 1977, 1980 e 1985. Rev.Saúde Pública., v. 24, n. 6, p. 481-9, 1990.

11. MARCONDES, E. Normas para o diagnóstico e a classificação dos distúrbios de crescimento e da nutrição: última versão. Pediatria. v. 4, n. 4, p. 307-26, 1982.
12. ORGANIZACIÓN PANAMERICANA DE LA SALUD. Fecundidad en la adolescencia: causas, riesgos y opciones. Washington, 1988. 69p. (Cuaderno Técnico n.12).

13. SABOIA, A.N.; RIBEIRO, R. (coord.) Crianças e adolescentes: indicadores sociais. Rio de Janeiro: IBGE, 1989. v. 3.

14. SÃO PAULO (Estado). Sistema Unificado e Descentralizado de Saúde. Programa de Atendimento Integral à Saúde do Adolescente. Centro de Apoio ao Desenvolvimento de Assistência Integral à Saúde. Metas e resultados atingidos: março de 1986 a março de 1991. São Paulo, s.d. (mimeografado).

15. SILVA, R.M.R. da (coord.) Crianças e adolescentes: indicadores sociais. Rio de Janeiro: IBGE, 1987. v. 1.

16. - (coord.) Crianças e adolescentes: indicadores sociais. Rio de Janeiro: IBGE, 1992. v. 4.

17. SOUZA, M.de F.M. de; KALICHMAN, A.O. Vigilância à saúde: epidemiologia, serviços e qualidade de vida. IN: SOUZA, M.de F.M. de et al. Vigilância à saúde: textos. São Paulo, 1992. (Cadernos CEFOR, série textos, 2) p. 1-21.

18. YUNES, J.; PRIMO, E. Características de la mortalidad de los adolescentes brasileños. In: ORGANIZACIÓN PANAMERICANA DE LA SALUD. La salud del adolescente y el joven en las Americas. Washington, 1985. Parte 3, p. 129-38. (Publicación científica n. 489). 